\title{
A evolução recente do desemprego no mercado de trabalho brasileiro
}

Luma de Oliveira*

Marina Silva da Cunha*

RESUMO - Este trabalho tem como objetivo analisar a tendência recente do desemprego no Brasil, com base nos dados da Pesquisa Mensal do Emprego do Instituto Brasileiro de Geografia e Estatística (PME/IBGE), no período de 2002 até 2009. Os resultados do trabalho indicam que a taxa de desemprego tem tendência negativa no período analisado. Embora, entre 2008 e 2009 , o nível de desemprego tenha aumentado, como um reflexo da crise financeira internacional. Além disso, pôde-se verificar que essa crise atingiu de forma mais intensa os indivíduos do sexo masculino, adultos, mais qualificados e da Região Metropolitana de São Paulo.

Palavras-chave: Taxa de desemprego. Composição do desemprego. Crise financeira internacional.

\section{INTRODUÇÃO}

Nas últimas décadas a economia brasileira vem passando por importantes transformações, tais como o processo de globalização e os planos de estabilização, desta forma o mercado de trabalho tem passado por mudanças relevantes e, sobretudo, se mostrado incapaz de gerar postos de trabalho suficientes para atender a oferta de trabalho (RAMOS \& VIEIRA, 2000).

$\mathrm{Na}$ década de 1980, a taxa de desemprego permaneceu em um nível relativamente baixo. Conforme Amadeo et al. (1994), essa taxa esteve em torno de 5\% a. a., nesse período. A partir da década de 1990, ocorreu um aumento nas taxas de desemprego no País. No início dessa década, mais especificamente em 1992, a taxa de desemprego estava em 7,2\% e, em 2005, em 10,2\%. No entanto, conforme Ramos (2007), a taxa de desemprego está mais estável na década de 2000, em um patamar inferior ao observado em 1999.

Entre os jovens o nível de desemprego é mais alto. Segundo Camargo e Reis (2005), este fato pode ser devido à assimetria de informações, isto é, os empregadores dispõem de pouca informação sobre o perfil, capacidade produtiva e experiência dos indivíduos jovens.

Para Hoffmann e Leone (2004), ao acompanhar o processo de industrialização e urbanização a participação de mulheres no mercado de trabalho no período 1970-1990 aumentou. Para os autores, na década de 1990 o crescimento da participação feminina no mercado

\footnotetext{
* Graduanda do curso de Ciências Econômicas da Universidade Estadual de Maringá. É bolsista do programa PIBIC. Endereço eletrônico: luma_de_oliveira@hotmail.com.

** Doutora em economia aplicada pela Universidade de São Paulo. É professora associada do Departamento de Economia da Universidade Estadual de Maringá. Endereço eletrônico: mscunha@uem.br.
} 
de trabalho não foi acompanhado por uma criação na mesma medida de postos de trabalho, isto é, o mercado de trabalho não conseguiu absorver toda a população economicamente ativa feminina.

Neste contexto, o objetivo deste trabalho é analisar a tendência recente do desemprego no mercado de trabalho brasileiro no período de 2002 a 2009, com base nas informações da Pesquisa Mensal do Emprego do Instituto Brasileiro de Geografia e Estatística (PME/IBGE).

Destaca-se que, conforme Ramos (2007), o desemprego pode ser considerado a principal variável de referência para o mercado de trabalho, uma vez que permite compreender o seu comportamento. Assim, quando a taxa de desemprego está em um baixo patamar, sugere-se que o mercado de trabalho está passando por um bom momento e, por outro lado, quando está alta a avaliação é o contrário.

\section{BASE DE DADOS}

Conforme salientado, neste trabalho são utilizadas as informações da Pesquisa Mensal do Emprego do IBGE, que permite descrever o comportamento do mercado de trabalho no Brasil metropolitano.

Neste estudo o desemprego é analisado considerando alguns fatores: gênero, idade, escolaridade e região. Inicialmente, são estudados os diferenciais de desemprego entre os homens e as mulheres. Para a idade, são consideradas quatro categorias: os jovens, que tem idade entre 15 e 17 anos e de 18 a 24 anos, os adultos com 25 até 49 anos e aqueles, com 50 anos ou mais. Com relação à escolaridade, são consideradas três categorias: os não-qualificados, que estudaram menos de oito anos, os trabalhadores semiqualificados, com oito até onze anos de estudo e os qualificados com mais de onze anos de estudo. Por fim, as informações da PME/ IBGE permitem estudar o desemprego nas principais regiões metropolitanas brasileiras, que são as regiões metropolitanas de Recife, Salvador, Rio de Janeiro, Porto Alegre, São Paulo e Belo Horizonte.

\section{A TAXA E A COMPOSIÇÃO DO DESEMPREGO NO BRASIL}

A evolução da taxa de desemprego nas regiões metropolitanas do Brasil, de março de 2002 a dezembro de 2009, pode ser observada no gráfico 1, em que se verifica tendência decrescente, mais acentuada a partir do ano de 2004. Nota-se uma sazonalidade anual na taxa de desemprego no País, com níveis maiores no meio do ano do que no seu final e início. Por exemplo, no ano de 2003, enquanto em julho a taxa de desemprego estava em 12,8\%, em dezembro alcançou 10,9\% à menor taxa apresentada ao longo do ano. 
Uma explicação para este fato pode ser dada pelo trabalho temporário, em que são comuns contratos com três meses, podendo ser estendidos por mais três, relacionada às datas comemorativas de final e início de cada ano. Conforme Alves (2002), o trabalhador, neste caso, possui os mesmos deveres de qualquer outro trabalhador, porém não tem direito a multa de 40\% sobre o FGTS nem sobre o aviso prévio, isto porque a data de demissão já é conhecida no ato da contratação.

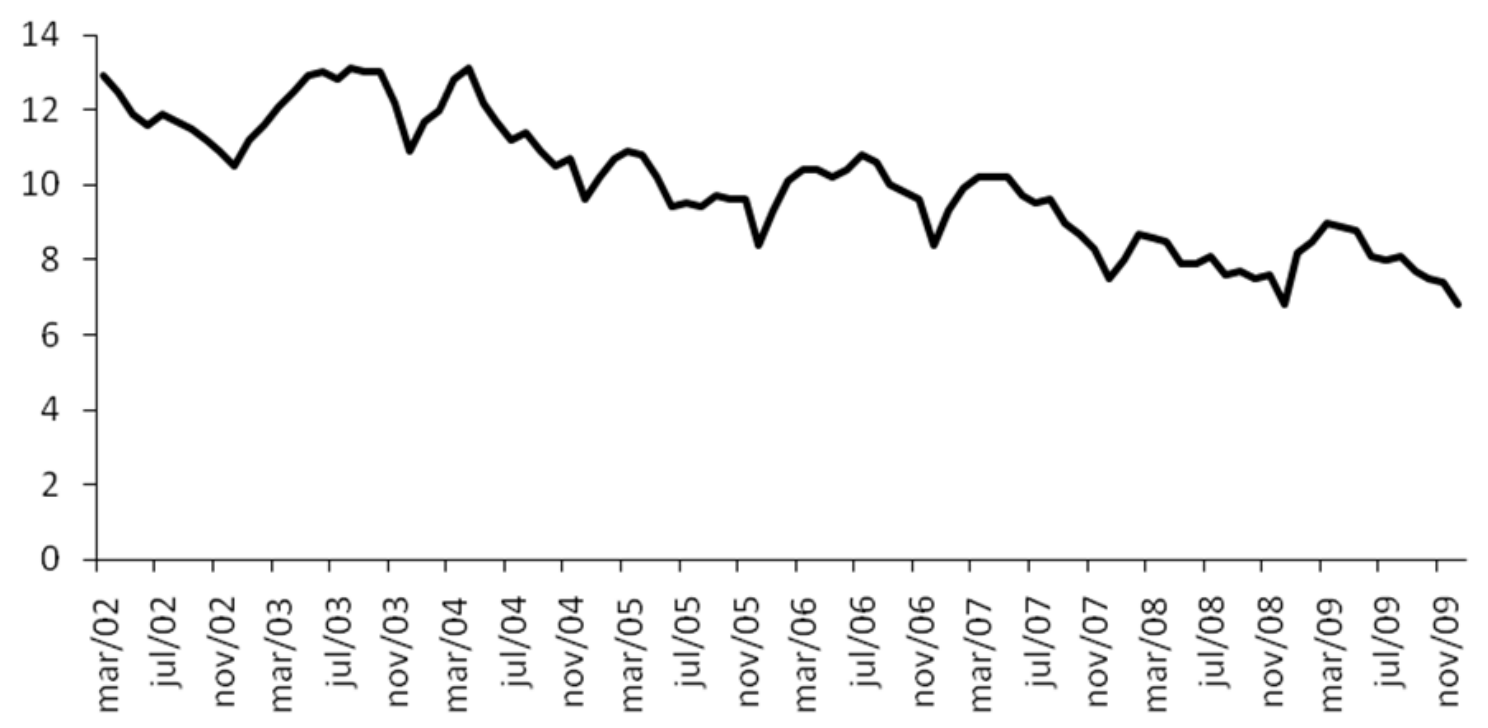

FONTE: Elaborado com base nas informações da PME/IBGE.

Destaca-se, que as taxas mensais de desemprego no ano de 2009 foram maiores que as alcançadas em 2008, enquanto que a média em 2008 foi de 7,9\%, em 2009 foi de 8,1\%, indicando os reflexos imediatos da crise financeira internacional ${ }^{1}$. No Brasil, a escassez de crédito externo repercutiu sobre os indicadores de atividade econômica com queda da produção e aumento do desemprego, sugerindo que consumidores e empresários tiveram uma postura cautelosa nas decisões de consumo e investimento, segundo Alves e Veríssimo (2009).

Na Tabela 1, pode-se observar a taxa e a composição do desemprego, segundo algumas categorias. Verifica-se que, em média, em 2002, o desemprego entre os homens era de $9,9 \%$ e entre as mulheres de 13,9\%, já, em 2009, era de 6,5\% e 9,9\%, respectivamente. Portanto, o diferencial nas taxas de desemprego de gênero diminuiu, embora o nível de desemprego entre 1 A crise financeira que se iniciou nos Estados Unidos e contaminou o resto do mundo, mais especificadamente a partir de setembro de 2008 com a quebra do banco de investimento Lehman Brothers, foi a crise mais grave sentida pela economia mundial nos últimos setenta e cinco anos, de modo que nenhum país deixou de sentí-la, mesmo que de formas diferentes. A desconfiança dos investidores quanto ao destino dos países fizeram estes trocarem suas aplicações para os ativos mais seguros como os títulos do tesouro norte-americano, o que acabou causando a queda dos preços dos ativos, elevação do risco de títulos dos mercados emergentes e depreciação das taxas de câmbio desses países. (ALVES \& VERÍSSIMO, 2009). 
as mulheres ainda seja maior. Na composição do desemprego, as mulheres também se apresentam com a maior proporção entre os desempregados.

Quando analisamos a Tabela 1 nota-se um aumento da proporção de mulheres desempregadas ao longo dos anos. No ano de 2009, com os reflexos da crise financeira internacional, a proporção de mulheres entre os indivíduos desempregados diminuiu, o que pode estar indicando uma saída delas do mercado de trabalho. Conforme Menezes-Filho et al. (2004), os homens tendem a permanecer mais no mercado de trabalho em condições adversas.

TABELA 1 - TAXA DE DESEMPREGO E COMPOSIÇÃO DO DESEMPREGO NO MERCADO BRASILEIRO PARA AS CATEGORIAS GÊNERO, IDADE, ANOS DE ESTUDO E REGIÕES METROPOLITANAS

\begin{tabular}{|c|c|c|c|c|c|c|c|c|}
\hline Categorias & 2002 & 2003 & 2004 & 2005 & 2006 & 2007 & 2008 & 2009 \\
\hline \multicolumn{9}{|c|}{ Taxa de Desemprego Anual } \\
\hline \multicolumn{9}{|l|}{ Gênero } \\
\hline Homem & 9,89 & 10,07 & 9,10 & 7,78 & 8,17 & 7,43 & 6,10 & 6,52 \\
\hline Mulher & 13,93 & 15,15 & 14,43 & 12,38 & 12,26 & 11,59 & 10,04 & 9,93 \\
\hline \multicolumn{9}{|l|}{ Idade } \\
\hline 15 a 17 & 34,19 & 38,15 & 35,44 & 33,33 & 32,62 & 31,99 & 28,8 & 28,65 \\
\hline 18 a 24 & 21,56 & 23,37 & 22,58 & 20,67 & 21,06 & 19,84 & 16,69 & 17,33 \\
\hline 25 a 49 & 9,00 & 9,38 & 8,73 & 7,38 & 7,57 & 7,21 & 6,28 & 6,61 \\
\hline 50 ou mais & 4,94 & 5,28 & 4,70 & 3,74 & 3,72 & 3,23 & 2,79 & 3,00 \\
\hline \multicolumn{9}{|l|}{ Anos de estudo } \\
\hline Menos de oito & 12,07 & 12,01 & 10,57 & 8,85 & 8,94 & 8,08 & 6,76 & 6,64 \\
\hline Oito a onze & 15,45 & 16,59 & 15,8 & 13,42 & 13,66 & 12,6 & 10,68 & 10,53 \\
\hline Mais de onze & 9,63 & 10,73 & 10,37 & 9,12 & 9,27 & 8,82 & 7,55 & 7,96 \\
\hline \multicolumn{9}{|l|}{ Região Metropolitana } \\
\hline Recife & 7,75 & 7,74 & 7,78 & 7,8 & 7,76 & 7,78 & 7,84 & 7,86 \\
\hline Salvador & 7,42 & 7,5 & 7,6 & 7,68 & 7,73 & 7,84 & 7,9 & 8,04 \\
\hline Belo Horizonte & 10,22 & 10,27 & 10,34 & 10,39 & 10,43 & 10,47 & 10,55 & 10,58 \\
\hline Rio de Janeiro & 10,05 & 9,19 & 9,03 & 7,72 & 7,88 & 7,15 & 6,78 & 6,13 \\
\hline São Paulo & 12,72 & 14,08 & 12,63 & 10,23 & 10,52 & 10,11 & 8,4 & 9,18 \\
\hline Porto Alegre & 8,39 & 8,4 & 8,38 & 8,34 & 8,32 & 8,28 & 8,25 & 8,23 \\
\hline \multicolumn{9}{|c|}{ Composição do Desemprego } \\
\hline \multicolumn{9}{|l|}{ Gênero } \\
\hline Homem & 47,67 & 45,34 & 43,68 & 43,43 & 44,76 & 43,38 & 41,90 & 43,54 \\
\hline Mulher & 52,34 & 54,66 & 56,33 & 56,57 & 55,25 & 56,62 & 58,09 & 56,47 \\
\hline \multicolumn{9}{|l|}{ Idade } \\
\hline 15 a 17 & 8,32 & 9,00 & 8,59 & 8,14 & 7,95 & 7,57 & 7,64 & 6,54 \\
\hline 18 a 24 & 36,77 & 36,53 & 37,36 & 38,56 & 38,19 & 37,73 & 36,08 & 35,27 \\
\hline 25 a 49 & 48,01 & 46,97 & 46,67 & 46,45 & 46,90 & 47,94 & 49,01 & 50,41 \\
\hline 50 ou mais & 6,21 & 6,62 & 6,63 & 6,39 & 6,42 & 6,19 & 6,64 & 7,32 \\
\hline \multicolumn{9}{|l|}{ Anos de estudo } \\
\hline Menos de oito & 36,25 & 33,23 & 29,94 & 27,75 & 26,41 & 24,18 & 22,50 & 20,32 \\
\hline Oito a onze & 26,94 & 26,94 & 26,90 & 26,07 & 25,76 & 25,12 & 24,58 & 23,21 \\
\hline Mais de onze & 36,82 & 39,84 & 43,16 & 46,19 & 47,81 & 50,70 & 52,92 & 56,46 \\
\hline \multicolumn{9}{|l|}{ Região Metropolitana } \\
\hline Recife & 9,67 & 7,77 & 7,50 & 9,22 & 10,18 & 11,97 & 11,42 & 11,24 \\
\hline Salvador & 9,67 & 10,23 & 10,72 & 12,46 & 10,73 & 11,97 & 11,42 & 11,24 \\
\hline Belo Horizonte & 9,16 & 8,90 & 9,57 & 9,22 & 9,09 & 8,84 & 9,00 & 8,70 \\
\hline Rio de Janeiro & 21,67 & 18,28 & 19,32 & 18,97 & 18,95 & 18,21 & 20,40 & 17,76 \\
\hline São Paulo & 45,84 & 48,41 & 46,69 & 43,89 & 44,40 & 45,90 & 45,35 & 48,59 \\
\hline Porto Alegre & 6,37 & 6,40 & 6,22 & 6,24 & 6,65 & 6,42 & 6,22 & 5,64 \\
\hline
\end{tabular}

FONTE: Elaborado com base nas informações da PME/IBGE. 
Para Ramos e Brito (2003), em um cenário favorável os empresários estão mais dispostos a fazer investimentos e, fazendo isto, incentivam os trabalhadores, que antes estavam afastados por desalento, a voltar a ofertar sua força de trabalho. Desta forma, uma mudança favorável pode resultar em um aumento de desemprego em função da redução dos trabalhadores em posição de desalento. Pode-se supor que as mulheres ao longo do período analisado, vendo uma conjuntura favorável, foram cada vez mais ofertando sua força de trabalho. Por outro lado, em um cenário desfavorável, como o da recente crise internacional, elas tenham reduzido sua oferta de trabalho, justificando a redução da sua taxa de desemprego, em 2009.

Embora a taxa de desemprego atinja maior nível entre os mais jovens, a maior proporção de desemprego está entre os adultos. No ano de 2002, enquanto entre os mais jovens, de 15 a 17 anos, a taxa de desemprego era de 34,19\% e representavam 8,32\% do total de desempregados, entre os adultos, de 24 a 49 anos, esses percentuais eram iguais a 9,0\% e 48,01\%, respectivamente. Este fato pode ser explicado pela proporção de indivíduos nesta faixa etária na PEA (População Economicamente Ativa). Segundo Ramos (2002) há um crescimento dos adultos na PEA, por exemplo, a faixa etária de 40 a 49 anos cresceu de 2,9 milhões em 1991 para 4,2 milhões em 2001. Além disso, pode ser observado que as categorias que sofreram mais intensamente com a crise financeira internacional foram aqueles de 25 até 49 anos e 50 anos ou mais.

Conforme Flori (2003), os principais responsáveis pela alta taxa de desemprego entre os jovens são aqueles que já trabalharam, mas trocam de emprego com maior frequência, e não os que estão em busca do primeiro emprego. Para Reis e Cortez (2005), outra explicação para o desemprego entre os jovens é a assimetria de informações, pois os empregadores têm informações limitadas sobre a produtividade dos trabalhadores mais jovens, em comparação com os trabalhadores que já acumularam experiência no mercado de trabalho.

A taxa de desemprego segundo os anos de escolaridade do indivíduo está maior para as pessoas que possuem de oito até onze anos de estudo. Este fato está de acordo com o trabalho de Camargo e Reis (2005), segundo o qual o desemprego é maior para os semiqualificados do que para os não-qualificados, ou seja, do que para as pessoas que não possuem escolaridade nenhuma as quais recorrem à informalidade. Porém a categoria com menor taxa de desemprego, os qualificados, com mais de onze anos de estudo, representam mais de $50 \%$ das pessoas desempregadas. Entre as explicações desse comportamento podem ser citadas a sua maior oferta no período recente e o maior salário de reserva desses indivíduos.

Ao final do período, em 2009, se verifica que embora a diferença nas taxas de desemprego entre as categorias de anos de estudo tenha caído, as pessoas de oito até onze anos de 
estudo ainda possuem a maior taxa, ou seja, 10,5\% contra 6,6\% e $8 \%$ das pessoas com até oito anos de estudo e com mais de onze, respectivamente. Além disso, a crise financeira de 2008 teve reflexos mais intensos nos indivíduos mais qualificados. Segundo Reis (2006), os choques agregados provocam aumentos relativamente maiores na taxa de desemprego dos trabalhadores qualificadas devido à maior rigidez salarial desse grupo.

A trajetória decrescente nas taxas de desemprego também é verificada nas seis Regiões Metropolitanas. Ao longo do período, a discrepância entre as taxas de desemprego das Regiões Metropolitanas diminuiu, pois enquanto, em média, em 2003, Salvador apresentava a maior taxa (16,68\%) o Rio de Janeiro tinha a menor (9,19\%). Portanto, uma diferença 7,49 p.p., em 2003, e, em 2009, essa diferença foi de apenas 5,18 p.p. As maiores proporções de desempregados estão nas Regiões metropolitanas do Rio de Janeiro e de São Paulo, este último por sua vez detém quase a metade das pessoas desempregadas das regiões analisadas. Embora a Região Metropolitana do Rio de Janeiro tenha uma das menores taxas de desemprego, o volume de desempregados representa $1 / 4$ do total analisado. Este fato pode ser explicado pela composição da PEA em cada região, em que o Rio de Janeiro também detém cerca de $25 \%$ do total. Os efeitos da crise financeira internacional foram mais fortes na Região Metropolitana de São Paulo, que foi a única com crescimento na proporção de desempregados, entre 2008 e 2009.

\section{CONCLUSÕES}

Os resultados do trabalho indicam que a taxa de desemprego tem tendência negativa no período analisado, de 2002 até 2009. Embora, como reflexo imediato da crise financeira internacional, a taxa de desemprego sofreu um aumento no seu nível de 2008 para 2009, atingindo cerca de $8 \%$, no final do período.

Verificou-se que os diferenciais de gênero, idade, escolaridade e regionais vêm se reduzindo. Ao longo do período analisado, a maior taxa de desemprego estava entre as mulheres, os mais jovens, os considerados semiqualificados, de 8 até 10 anos de estudo e os residentes na Região Metropolitana de Salvador. Por outro lado, a maior proporção dos desempregados também ficou entre as mulheres, mas entre os adultos, os indivíduos qualificados, com 11 anos ou mais de estudo, e residentes na Região Metropolitana do Rio de Janeiro.

Além disso, pôde-se verificar que a crise financeira de 2008 teve reflexos mais intensos nos indivíduos do sexo masculino, adultos, mais qualificados e da Região Metropolitana de São Paulo, sugerindo que os empresários optaram por reduzir seus custos, notadamente, entre aqueles indivíduos com os maiores salários. 


\section{REFERÊNCIAS}

ALVES, G. Trabalho, sindicalismo no Brasil: um balanço crítico da "década neoliberal" (19902000). Revista de Sociologia e Política, n.19, p. 71-94, nov. 2002.

ALVES, T. G. e VERÍSSIMO, M. P. Crise Financeira, Estado e Política Monetária: Uma abordagem principalmente Keynesiana. XXXVII Encontro Nacional de Pós-graduação em Economia, Foz do Iguaçu, 2009.

AMADEO, E.; CAMARGO, J. M.; GONZAGA, G.; BARROS, R.; MENDONÇA, R. A natureza e o funcionamento do mercado do mercado de trabalho brasileiro desde 1980. Rio de Janeiro: IPEA, 1994. (Texto para discussão, n. 353)

CAMARGO, J. REIS, M. C. Desemprego: custo da informação. Revista Brasileira de Economia. v. 59, n.3, p. 381-425, 2005.

CURI, A. Z.; MENEZES-FILHO, N. A. Os Determinantes das Transições Ocupacionais no Mercado de Trabalho Brasileira. XXXII Encontro Nacional da Associação Nacional de Pós-graduação em Economia, Salvador, 2004.

FLORI, P. M. Desemprego de Jovens no Brasil. 2003. Disponível em: < http://www.anpec. org.br/encontro2003/artigos/F09.pdf>. Acesso em: 10/10/2009.

HOFFMANN, R. LEONE, E. T. Participação da mulher no mercado de trabalho e desigualdade da renda domiciliar per capita no Brasil:1981-2002. Nova Economia, v. 2, n.14, p. 35-58, 2004.

IBGE. Instituto Brasileiro de Geografia e Estatística. Pesquisa Mensal do Emprego. Disponível em: < http://www.ibge.gov.br>. Acesso em: 10/10/2009.

RAMOS, L.; VIEIRA, M. L. Determinantes da desigualdade de rendimentos no Brasil nos anos 90: discriminação, segmentação e heterogeneidade dos trabalhadores. In: HENRIQUES, Ricardo (org.). Desigualdade e pobreza no Brasil. Rio de Janeiro: IPEA, p. 159-176, 2000.

RAMOS, C. A.; CARNEIRO, F. G. Os Determinantes da Rotatividade do Trabalho no Brasil: Instituições X Ciclos Econômicos. Revista Nova Economia, v.2, n. 12, p. 31-56, 2002.

RAMOS, C. A. Políticas de geração de emprego e renda justificativas teóricas, contexto histórico e experiência brasileira. Brasília: Unb, jan. 2003 (Texto para discussão, n. 277).

RAMOS, L. O desempenho recente do mercado de trabalho brasileiro: tendências, fatos estilizados e padrões espaciais. Rio de Janeiro: IPEA, jan. 2007, (Texto para discussão, n. 1255).

RAMOS, L. A Desigualdade de Rendimentos do Trabalho no Período Pós-Real: o Papel da Escolaridade e do Desemprego. Revista de Economia Aplicada, n.2, p. 281-301, 2007.

RAMOS, L.; BRITO, M.; O Funcionamento do Mercado de Trabalho Metropolitana Brasileiro no Período de 1991-2002: Tendências, Fatos Utilizados e Mudanças Estruturais. Rio de Janeiro: IPEA, p. 31-47, nov. 2003 (Nota técnica).

REIS, M. C. Os Impactos das Mudanças na Demanda por Trabalho Qualificado sobre o Desemprego por Nível de Qualificação durante os Anos Noventa no Brasil. Revista Brasileira de Economia, v. 60, n. 3, p. 297-319, 2006.

REIS, M. C.; CAMARGO, J. M. Desemprego dos jovens no Brasil: Os Efeitos da Estabilização da Inflação em um Mercado de Trabalho com Escassez de Informação. Revista Brasileira de Economia, v. 61, n. 41, p. 493-518, 2007. 
